\title{
Приоритеты внедрения электронных государственных сервисов по результатам опроса граждан в Санкт-Петербурге
}

\author{
В. А. Белый, П. В. Смирнова \\ Университет ИТМО \\ vladislaveitmo.ru, pvsmirnova@itmo.ru
}

\section{Аннотация}

В статье приводятся результаты опроса жителей Санкт-Петербурга с целью выявления их мнения о приоритетности сервисов «умного города». В результате исследования были выявлены наиболее востребованные электронные сервисы, а также определены факторы, влияющие на их восприятие населением. Исследование было проведено в марте 2020 года методом анкетирования по выборке, репрезентирующей население Санкт-Петербурга по полу и возрасту. Результаты показали, что в качестве наиболее актуальных жителями Санкт-Петербурга были отмечены электронные сервисы в сфере здравоохранения и медицины $(78 \%)$, сервисы безопасного города (70\%), электронные сервисы в сфере транспортного обслуживания двух типов: для пассажиров общественного транспорта (63\%) и владельцев личного транспорта (61\%).

Ключевые слова: электронное правительство, умный город, электронное участие, электронные сервисы, доверие власти

Библиографическая ссылка: Белый В.А., Смирнова П.В. Приоритеты внедрения электронных государственных сервисов по результатам опроса граждан в СанктПетербурге // Государство и граждане в электронной среде. Выпуск 4 (Труды XXIII Международной объединенной научной конференции «Интернет и современное общество», IMS-2020, Санкт-Петербург, 17 - 20 июня 2020 г. Сборник научных статей). - СПб: Университет ИТМО, 2020. С. 114-120. DOI: 10.17586/2541-979X-4$114-120$

\section{1. Введение}

Инструменты электронной коммуникации становятся неотъемлемой частью нашей жизни. Все большее число граждан имеет быстрый доступ к интернету и мобильным устройствам, позволяющим выходить в сеть практически из любого местоположения. В связи с этим возникают новые механизмы взаимодействия власти и общества и появляется необходимость адаптировать государственные сервисы к новым условиям. Ситуация с внедрением карантинных мероприятий в целях предупреждения эпидемии коронавируса только актуализировала эти планы. В России активно развиваются системы электронного правительства, которые представляют собой высокотехнологичные каналы, альтернативные традиционным: очному приему, обращениям по почте или по телефону. В настоящее время в Санкт-Петербурге обсуждается создание новых городских сетевых сервисов для граждан. Политика государства направлена на централизацию сервисов и создание системы, позволяющей быстро получить государственные и муниципальные услуги в электронной форме. Однако зачастую элементы электронного правительства воспроизводят проблемы традиционных каналов связи. Так, «Личный кабинет налогоплательщика» - один из популярных у граждан электронных сервисов, пока лишь 
сокращает бумажный документооборот для гражданина, но все еще воспроизводит проблемы традиционных каналов - длительное ожидание, необходимость заполнения множества отчетных документов аналогичных бумажным. В связи с этим возникают вопросы о дальнейших перспективах развития электронных сервисов и приоритетности. Для лучшего понимания их направления развития необходимо понимать спрос населения на те или иные порталы, выявить препятствия для их качественного внедрения и эффективного использования.

Центром технологий электронного правительства Института дизайна и урбанистики Университета ИТМО еще при старте реализации приоритетного проекта «Умный СанктПетербург» были проведены социологические опросы сотрудников органов власти и жителей города. Если в 2017 и 2018 годах опрос чиновников и горожан проводился посредством онлайн-анкетирования, то с 2019 года в качестве места для проведения опросов граждан была определена система многофункциональных центров в СанктПетербурге.

Статья представляет собой анализ результатов опроса жителей Санкт-Петербурга в марте 2020 года, выполненного с целью определения уровня востребованности городских сетевых сервисов и специфики электронного взаимодействия граждан с органами власти.

\section{2. Методика исследования}

Исследование проведено в рамках экспертно-аналитического компонента деятельности Проектного офиса «Умный Санкт-Петербург» в сотрудничестве с Комитетом по информатизации и связи Санкт-Петербурга и системой Многофункциональных центров оказания государственных и муниципальных услуг (МФЦ) методом анкетного опроса граждан, обратившихся за услугами в МФЦ. Исследование проводилось в шести районах города: в Василеостровском, Выборгском, Петроградском, Приморском, Московском, Фрунзенском в марте 2020 года. Анкета состояла из вопросов, позволяющих выявить параметры осведомленности, востребованности, приоритетности и доверия по отношению к электронным сервисам взаимодействия власти и граждан.

Данное эмпирическое исследование продолжает серию исследований, осуществленных в 2018-2019 гг. В результате первого исследования (ноябрь 2018) была получена информация об уровне восприятия концепции «Умного города» и понимании его составляющих жителями города - потенциальными пользователями сервисов [1]. Второй опрос (май 2019) был проведен для оценки доверия к использованию информационных технологий при взаимодействии через электронные порталы, формы электронных обращений, получения электронных услуг, электронного голосования и др. [2]. В результате, в частности, была выявлена необходимость уточнить приоритеты программы «Умный город» с учетом ожиданий разных возрастных групп граждан.

Опрос, результаты которого представляются в статье, был проведен в марте 2020 года. Анкета содержала параметры для оценки приоритетности электронных сервисов взаимодействия с властью и получения государственных, общественных и коммерческих услуг, решения городских проблем и участия в управлении городом. Респондентам было предложено указать степень приоритетности электронных сервисов как для себя лично, так и для развития городской среды. При расчете выборочной совокупности использовались данные о численности населения, его возрастном и половом составе, размещенные на сайте Управления Федеральной службы статистики по г. СанктПетербургу и Ленинградской области. Так, в ходе исследования был определен размер выборочной совокупности, которая будет являться репрезентативной, то есть позволит нам на ее основе оценивать характеристики совокупности $(5,39$ млн жителей по официальным данным на начало 2019 г.) [3]. При расчете характеристик простой случайной выборки был определен еe размер в 600 респондентов (при уровне достоверности в 95\%, ошибка выборки - 4\%) [4]. Однако из-за начавшейся пандемии 
коронавируса пришлось завершить опрос в МФЦ раньше, чем планировалось и число опрошенных респондентов было сокращено до 564. Это привело к несколько большей ошибке выборки - в 4,1\%.

Выборка репрезентирует население Санкт-Петербурга по полу и возрасту и соответствует половозрастной структуре респондентов: из опрошенных 43,6\% составляют мужчины, а 56,4\% - женщины. Возрастная структура была следующей: 18-30 лет - 21,8\%, $31-45$ лет - 31\%, 46-59 лет - 27,5\%, 60 и старше лет - 19,7\%.

Опрос проводился путем личного анкетирования интервьюерами в помещении МФЦ с фиксацией половозрастных характеристик респондентов в соответствии с требованиями соблюдении выборки. Каждый интервьюер, ответственный за опрос в конкретном МФЦ, ориентировался на сводную таблицу распределения по полу и возрасту тех посетителей, которых необходимо опросить на данной площадке. Это позволило соблюсти требования соблюдения репрезентативности общей выборки исследования. Проведение исследования было согласовано с руководством ГУ МФЦ, на информационных мониторах присутствовала бегущая строка с просьбой к посетителям принять участие в опросе, что, несомненно, повысило готовность граждан отвечать на вопросы интервьюеров. Респондентам предлагалось ответить на вопросы анкеты либо самостоятельно заполняя анкету, либо отвечая на вопросы интервьюера с фиксацией ответов в системе Anketolog.ru. После завершения опроса и проверки соблюдения позиций выборки средствами указанной системы был получен текстовый отчет и база данных в формате MS Excel. Простые распределения и визуализация графиков были получены средствами Excel, более сложные вычисления (анализ таблиц сопряженности) осуществлялись с помощью программы SPSS.

\section{3. Результаты исследования}

Анкета опроса включала позиции, позволившие зафиксировать уровень проникновения Интернета в жизнь горожан в сравнении с результатами исследования 2018 г. Был зафиксирован устойчивый рост коннективности: в 2020 г., 32\% респондентов ответили, что постоянно находятся в онлайне $(26 \%$, в 2018 г.) и 54\% пользуются Интернетом ежедневно (по сравнению с 41\% в 2018 г.). Данные, представленные в диаграммах на рисунке 1 наглядно демонстрируют, что все больше жителей Санкт-Петербурга пользуются Интернетом, что создает важные предпосылки для внедрения сервисов «Умного города» и является характеристикой, косвенно влияющей на уровень востребованности этих электронных сервисов в Санкт-Петербурге.
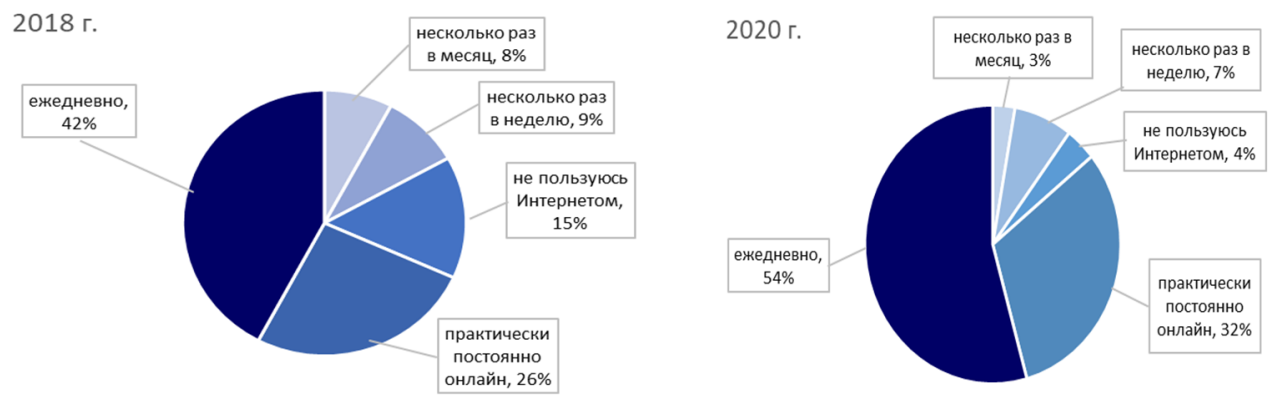

Рис. 1. Распределение ответов на вопрос «Как часто Вы пользуетесь Интернетом?» (данные ЦТЭП ИДУ Университета ИТМО, 2018 и 2020, в процентах)

Первый блок вопросов был связан с задачей выявления мнения горожан о приоритетности внедрения конкретных групп электронных сервисов. Список включенных в анкету сервисов был согласован с Комитетом по информатизации и связи Санкт- 
Петербурга и тем самым отражал текущие планы по развитию цифровой инфраструктуры города. Перечень сервисов и результаты опроса представлены на графике (см. рис. 2).

По данным исследования в качестве наиболее актуальных жителями Санкт-Петербурга были отмечены электронные сервисы в сфере здравоохранения и медицины (78\%), на втором месте - сервисы безопасного города (70\% - помощь в экстренных ситуациях, взаимодействие с участковыми и т.п.). На третьем месте оказались электронные сервисы в сфере транспортного обслуживания двух типов: для пассажиров общественного транспорта (63\%) и владельцев личного транспорта (61\%). Важно отметить, что необходимость развития порталов гражданских инициатив отметило всего $40 \%$ респондентов - среди всех сервисов это наименьший показатель актуальности, что косвенным образом свидетельствует о низком уровне развития гражданского общества.

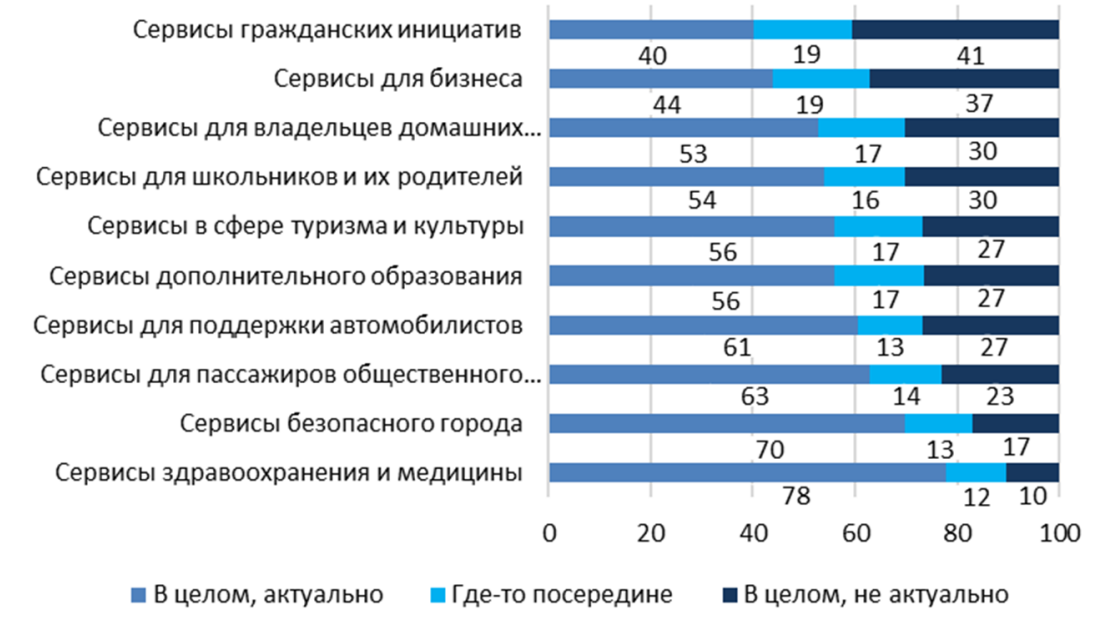

Рис. 2. Распределение ответов на вопрос «В какой степени появление следующих электронных сервисов было бы актуально и полезно лично для Вас»

(данные ЦТЭП ИДУ Университета ИТМО, 2020 г., в процентах)

В ходе опроса респондентам было предложено оценить степень своего согласия (или несогласия) с некоторыми утверждениями (табл. 1). В таблице представлены результаты оценки гражданами некоторых высказываний, содержащих утверждения. Проанализируем полученные результаты, разделив их на три группы значений. Оценки «скорее согласен» и «полностью согласен» будем считать положительными, «скорее не согласен» и «полностью не согласен» - отрицательными, а отметку 3 - нейтральной.

Таким образом, рассматривая оценки первого высказывания, можно отметить, что по данным нашего опроса органам власти города доверяют $25 \%$ респондентов, а не доверяют - 40\%. В условиях ощущений кризиса и неблагоприятной социально-экономической обстановки данные цифры являются вполне объяснимыми. Однако при анализе перспектив развития сервисов электронного участия важнейшим параметром является уровень доверия населения к взаимодействию с властью посредством интернеттехнологий. Процент согласных и не согласных граждан со вторым высказыванием в таблице («Я, в целом, доверяю взаимодействию с властью посредством интернет-технологий») оказался равным 33\%. При этом «скорее несогласных» оказалось гораздо больше «совершенно не согласных». По оценкам третьего высказывания из суммирования 1 и 2 колонки получается, что половина жителей Санкт-Петербурга (51\%) не согласна с тем, что Интернет позволяет решать проблемы коррупции в органах государственной власти.

Почти половина (45\%) горожан считает, что личный прием надежнее дистанционного взаимодействия с органами власти. При этом $36 \%$ отметили, что не получат желаемого результата, взаимодействуя с органами власти посредством сети Интернет. Поровну 
разделились согласные и не согласные с тем, что Интернет помогает быстрее доносить до органов власти свои личные проблемы.

Эти результаты показывают, что в настоящее время ещё невозможно планировать отмену очного способа взаимодействия граждан с органами власти.

Таблица 1. Степень согласия с утверждениями (данные ЦТЭП ИДУ Университета ИТМО, в процентах)

\begin{tabular}{|c|c|c|c|c|c|}
\hline \multirow{2}{*}{ Высказывание } & \multicolumn{5}{|c|}{ Степень согласия * } \\
\hline & 1 & 2 & 3 & 4 & 5 \\
\hline В целом я доверяю органам власти Санкт-Петербурга & 18 & 22 & 35 & 16 & 9 \\
\hline $\begin{array}{l}\text { Я, в целом, доверяю взаимодействию с властью посредством } \\
\text { интернет-технологий }\end{array}$ & 9 & 24 & 34 & 18 & 15 \\
\hline $\begin{array}{l}\text { Интернет позволяет решать проблемы коррупции в органах } \\
\text { государственной власти }\end{array}$ & 30 & 21 & 27 & 13 & 9 \\
\hline $\begin{array}{l}\text { Я считаю, что личный прием по-прежнему является более } \\
\text { надежным способом взаимодействия с органами власти, чем } \\
\text { взаимодействие через интернет-сервисы }\end{array}$ & 9 & 14 & 32 & 20 & 25 \\
\hline $\begin{array}{l}\text { При взаимодействии с органами власти через Интернет, по } \\
\text { сравнению с личными контактами, я рискую не получить } \\
\text { желаемого результата }\end{array}$ & 11 & 18 & 35 & 21 & 15 \\
\hline $\begin{array}{l}\text { Интернет помогает таким людям как я быстрее доносить до } \\
\text { органов власти свои личные проблемы и решать их }\end{array}$ & 15 & 16 & 36 & 23 & 9 \\
\hline $\begin{array}{l}\text { Я считаю, что могу быстро научить знакомого пользоваться } \\
\text { Интернет-ресурсами для взаимодействия с органами власти }\end{array}$ & 14 & 15 & 29 & 24 & 19 \\
\hline $\begin{array}{l}\text { Я могу порекомендовать знакомому интернет-ресурсы для } \\
\text { взаимодействия с органами власти, которыми лично пользуюсь }\end{array}$ & 15 & 14 & 31 & 24 & 17 \\
\hline $\begin{array}{l}\text { Часто мне приходится довольно долго разбираться с тем, как } \\
\text { работает тот или иной интернет-сервис, через которые я } \\
\text { взаимодействую с органами власти }\end{array}$ & 18 & 21 & 30 & 18 & 13 \\
\hline
\end{tabular}

Примечание: * Степень согласия фиксируется от 1 до 5, где 1 - совершенно не согласен, 5 - полностью согласен.

В рамках исследования были получены данные о том, насколько комфортны и удобны для использования уже функционирующие электронные сервисы. Можно отметить, что $41 \%$ респондентов могут порекомендовать знакомым интернет-ресурсы взаимодействия с органами власти, которыми лично пользуются, а 43\% утверждают, что могут быстро научить пользоваться такими ресурсами. При этом довольно значительная часть (39\%) отметили, что приходится довольно долго разбираться с тем, как работают данные электронные ресурсы.

Следует также отметить, что нейтральные оценки этим высказываниям поставили достаточно много респондентов - около трети (от 27 до 36\%). Можно было бы предположить, что это люди, которые еще не освоили электронные технологии и имеющие незначительный опыт работы в Интернете, однако данные, представленные в диаграмме на рис. 1, не позволяют сделать такое допущение. Совокупно доля тех, кто активно используют электронные технологии в своей жизни, составляет в СанктПетербурге около 85\%. Видимо достаточно высокая доля неопределенных ответов может быть следствием осторожного отношения и недоверия к власти как таковой, что подтверждается и распределением оценок к суждению «В целом я доверяю органам власти Санкт-Петербурга» (доверяют 25\% и не доверяют 40\%).

\section{4. Заключение и промежуточные выводы}

Настоящая статья представляет некоторые данные и промежуточные результаты их обработки. Следует отметить, что полученные результаты будут проанализированы и 
обсуждены с участием экспертов Проектного офиса «Умный Санкт-Петербург», представляющих научно-образовательное сообщество, ИТ-компании и органы власти.

В ходе исследования были выявлены наиболее востребованные по мнению горожан электронные сервисы, предлагаемые для внедрения в рамках совершенствования цифровой инфраструктуры Санкт-Петербурга. Следует отметить, что опрос проходил в марте 2020 г. в обстановке роста озабоченности населения города надвигающейся сложной эпидемиологической ситуацией в связи с развитием пандемии COVID-19. Это обстоятельство, несомненно, повлияло на результаты опроса горожан. В частности, превалирование сервисов здравоохранения и безопасности может быть объяснено именно этим фактором. Но такой «сдвиг» в оценках, на наш взгляд, не может считаться неким «шумом», т.к. отражает реальную ситуацию в общественном сознании. И последующие события только подтверждают тенденции усиления внимания именно к значимости задач здравоохранения и общественной безопасности. И несколько месяцев карантина продемонстрировали рост востребованности электронных сервисов в различных сферах жизнедеятельности.

Результаты исследования позволяют сформулировать вывод, что недоверие к электронным государственным сервисам может быть обусловлено не только общим уровнем недоверия к власти и ее инициативам, но и низким уровнем знаний граждан. Для эффективной интеграции сервисов «умного города» в жизнь необходима комплексная программа повышения интернет-грамотности населения и удобства (дружественности) сервисов для пользователей при их создании и развитии. Важным фактором, который, правда выходит за пределы сферы цифровизации, является уровень доверия к власти как таковой.

Работа выполнена при поддержке Российского научного фонда, проект №18-18-00360 «Электронное участие как фактор динамики политического процесса и процесса принятия государственных решений».

\title{
Литература
}

[1] Видясова Л.А., Тенсина Я.Д. Исследование доверия жителей Санкт-Петербурга к использованию информационных технологий для взаимодействия с органами власти // International Journal of Open Information Technologies. 2020. T. 8, № 1. C. 42-46.

[2] Видясова Л.А., Смирнова П.В. Исследование образа умного города глазами жителей Петербурга // Информационные ресурсы России. 2019. № 2(168). С. 35-38.

[3] Изменение численности населения на начало года [2019] / Петростат. - URL: https://petrostat.gks.ru/storage/mediabank/Возраст-пол\%20нас\%20СПб\%202019.pdf (дата обращения 15.02.2020).

[4] Рабочая книга социолога / Под общ. ред. и с предисл. Г.В. Осипова. М.: Книжный дом «Либриком». 2009. С. 212.

\section{Priorities for E-Government Services Implementation: Survey Results from St. Petersburg}

\author{
V. A. Belyi, P. V. Smirnova
}

ITMO University

The article presents the results of a survey of residents of St. Petersburg. The most demanded electronic services were revealed, and factors affecting their perception by the population were identified. The study was conducted in March 2020 using the survey method. The sample 
represents the population of St. Petersburg by gender and age. The results showed that the most relevant were electronic services in the field of healthcare and medicine $(78 \%)$, safe city services $(70 \%)$, electronic services in the field of transport services $(63 \%$ for passengers of public transport and $61 \%$ for owners of private vehicles).

Keywords: e-government, smart city, e-participation, e-services, public trust in government

Reference for citation: Belyi V.A., Smirnova P.V. Priorities for the E-Government Services Implementation: St. Petersburg Survey Results // The State and Citizens in the Electronic Environment. Vol. 4 (Proceedings of the XXIII International Joint Scientific Conference «Internet and Modern Society», IMS-2020, St. Petersburg, June 17-20, 2020). - St. Petersburg: ITMO University, 2020. P. 114-120. DOI: 10.17586/2541-979X-4-114-120

\section{Reference}

[1] Vidyasova L.A., Tensina Ya.D. Issledovanie doveriya zhitelej Sankt-Peterburga k ispolzovaniyu informacionnyh texnologij dlya vzaimodejstviya $\mathrm{s}$ organami vlasti // International Journal of Open Information Technologies. 2020. T. 8, № 1. S. 42-46. (in Russian).

[2] Vidyasova L.A., Smirnova P.V. Issledovanie obraza umnogo goroda glazami zhitelej Peterburga // Informacionnye resursy Rossii. 2019. № 2(168). S. 35-38. (in Russian).

[3] Izmenenie chislennosti naseleniya na nachalo goda [2019] / Petrostat. - URL: https://petrostat.gks.ru/storage/mediabank/Vozrast-pol\%20nas\%20SPb\%202019.pdf （in Russian).

[4] Rabochaya kniga sociologa / Pod obshch. red. i s predisl. G.V. Osipova. M.: Knizhnyj dom «Librikom». 2009. S. 212. (in Russian). 